\title{
Uterine receptivity and the plasma membrane transformation
}

\author{
Christopher R MURPHY \\ Department of Anatomy and Histology, The University of Sydney, NSW 2006. Australia.
}

\begin{abstract}
This review begins with a brief commentary on the diversity of placentation mechanisms, and then goes on to examine the extensive alterations which occur in the plasma membrane of uterine epithelial cells during early pregnancy across species. Ultrastructural, biochemical and more general morphological data reveal that strikingly common phenomena occur in this plasma membrane during early pregnancy despite the diversity of placental types-from epitheliochorial to hemochorial, which ultimately form in different species. To encapsulate the concept that common morphological and molecular alterations occur across species, that they are found basolaterally as well as apically, and that moreover they are an ongoing process during much of early pregnancy, not just an event at the time attachment, the term 'plasma membrane transformation' is suggested which also emphasises that alterations in this plasma membrane during early pregnancy are key to uterine receptivity.
\end{abstract}

Keywords: uterine epeithelial cells, membrane tranformation.

\section{INTRODUCTION}

Contact between the plasma membrane of uterine epithelial cells and that of the trophoblast is a common beginning to implantation in most species studied so far. This is perhaps not surprising since uterine epithelial cells are the first site of contact between maternal and foetal tissue at the beginning of blastocyst attachment and implantation. The similarities in these early events of the uterine response during early pregnancy and placentation however, go further than mere contact between opposing surfaces. A now considerable body of evidence indicates that the behaviour of the plasma membrane of the uterine epithelial cells during early pregnancy has many common aspects across species ranging from viviparous lizards to human beings and that moreover, these similarities exist regardless of the placental type which ultimately develops. This review pays special attention to events at the cellular level in uterine epithelial cells and to the plasma membrane in particular, but does so within the wider context of uterine receptivity for implantation across species.

\section{THE PLASMA MEMBRANE OF UTERINE EPITHELIAL CELLS IN ANIMALS}

Most studies to date on the plasma membrane of uterine

${ }^{*}$ Correspondence: Christopher R MURPHY

Tel: (61) 29351 4128, Fax: (61) 293512813

E-mail: histology@anatomy.usyd.edu.au epithelial cells and nearly all those involving experimental manipulations have been conducted in rodents thus this review begins with studies on rodents and then proceeds to look at other animals including humans.

\section{The apical plasma membrane in rodents}

The plasma membrane of uterine epithelial cells undergoes major changes in appearance in response to ovarian hormones and these changes are most obviously seen in changes to microvilli on the apical surface of the cells. These microvilli were the focus of many early ultrastructural studies and established the dynamism so characteristic of this plasma membrane. With progesterone alone, short regular microvilli are characteristically present whereas oestrogen alone typically results in long thin regular microvilli. Under the influence of either hormone alone, change in the apical plasma membrane is mostly limited to alterations in the height and frequency of microvilli [1, 2, 3 for review]. However, during early pregnancy when progesterone and oestrogen act together in the peri-implantation period leading to uterine receptivity for implantation of the blastocyst, the apical plasma membrane of uterine epithelial cells undergoes a more marked form of structural change during which over the several days of early pregnancy, and beginning as early as $\mathrm{d} 2$ of pregnancy, it gradually loses regular microvilli and becomes very flat $[2,4-7]$. Indeed, the membranes of uterine epithelial and trophoblast cells in the implantation chamber 
come to run more or less parallel all along the area of contact as more generally do the membranes of opposing uterine epithelial cells outside the implantation chamber especially in species with uterine closure $[8,9]$. This latter appearance is only seen during early pregnancy and is quite diagnostic for uterine receptivity for implantation in many species $[18,19]$.

\section{The apical plasma membrane in rodents: experimental manipulations}

Several different types of experiments in rats and mice have established that the above-described membrane changes are essential if blastocysts are to begin implantation successfully.

Nilsson [1], Ljungkvist [2] and Ljungkvist and Nilsson [10] performed a carefully timed series of experiments with both hormone injections to ovariectomized virgin rats and normally pregnant rats in which attachment had been delayed by ovariectomy on d 4 of pregnancy. They found that in either case, blastocysts were only able to begin implantation when the apical membrane flattening was present. Since this appearance is found in uterine epithelial cells during pseudopregnancy in both mice [8] and rats [9] and can also be induced in virgin ovariectomized rats treated with ovarian hormones in the absence of blastocysts $[2,7,11]$, it must be a maternal response not requiring a blastocyst for its occurrence. This view is further strengthened by the observation that the apical plasma membrane undergoes the same sequence of changes (although perhaps according to a slightly different schedule) whether it is opposed to a blastocyst or to uterine epithelial cells from the other side of the uterus $[2,4,5,7-9,13$, 14]. Contact with another cell surface is also apparently unnecessary because the same appearance is seen in appropriately stimulated uterine epithelial cells opposed to foreign objects [15]. In all cases, the hormonal requirements for pregnancy worked out by Psychoyos [16] were the same ones necessary for the apical membrane flattening.

Adding weight to the view that these membrane alterations are of functional importance for uterine receptivity are the experiments of Ljungkvist [17] who showed that amounts of oestrogen which were too high to allow implantation when acting on a progesterone primed uterus also prevented development of the membrane flattening. Similarly, Smith [18] has also shown that ageing mice which lack the apical membrane flattening are unable to support implantation and Png and Murphy [19] have established that regular microvilli begin to return to the apical plasma membrane very soon after the period of uterine receptivity for attachment thus also indicating the close association between the membrane changes and receptivity for attachment.
Collectively, these experimental manipulations strongly suggest that the characteristic 'transformation' of the apical plasma membrane of uterine epithelial cells from a microvillous to a flattened profile is a morphological sign of uterine receptivity as well as of key functional significance for uterine receptivity for blastocyst implantation in rodents at least.

\section{The apical plasma membrane in other animals}

Carefully conducted experimental manipulations are mostly lacking in other animals. Also lacking in most cases are studies which indicate to what extent the membrane changes occur more broadly, as they do in rodents, outside the implantation region itself. Nonetheless, there is considerable evidence that membrane changes with much in common with the apical flattening seen in rodents occurs in an impressive variety of animals.

In another rodent species, the Chinese hamster, Blankenship et al [21] found that attachment is quite similar to that in the rat with extensive remodelling of microvilli into irregular protrusions of the plasma membrane and Winterhager and Denker [22] also reported flattening and loss of microvilli in the rabbit. Potts and Racey [23] reported loss of apical microvilli and flattening of the apical plasma membrane in bats during early pregnancy such that uterine epithelial and trophoblast membranes ran parallel and Oliveira et al [24] have more recently reported on membrane flattening in bats. In the deer, Aitken et al [25] also found remodelling of microvilli and in the horse, Allen et al [26] described loss of microvilli and remodelling of the apical cell surface while in sheep, Guillomot et al [27] found loss of microvilli and formation of large rounded cytoplasmic protrusions of the apical plasma membrane as pregnancy progressed. In cats, Leiser and Koob [28] found that uterine epithelial cell surfaces became quite smooth during early pregnancy and in goats, Wango et al [29] reported that uterine epithelial cell microvilli were flattened and that membranes of that cell type and of the trophoblast came into very close contact. Indeed, in summarizing observations on many ruminants and ungulates in general, Wooding and Morgan [30] noted that uterine epithelial cell microvilli are completely displaced at attachment. In camels, Skidmore et al [31] showed that microvilli are completely lost on uterine epithelial cells at attachment only to be later reformed in a much longer profile as the interface of the mature epitheliochorial placenta and this very complete apical membrane flattening in camels has been elaborated on more recently [32]. In pigs, which also have an epitheliochorial placenta, Dantzer[20] commented on progressive loss of uterine epithelial microvilli and flattening of the apical plasma membrane into regions where uterine and trophoblast membranes ran parallel after which 
microvilli reformed to establish the mature epitheliochorial placenta and in one other epitheliochorial placenta, that of the marsupial mouse, Roberts and Breed [33] have also found flattening and loss of apical microvilli of uterine epithelial cells at attachment in a reaction they described as very similar to that of rats and mice. In the rhesus monkey, Enders et al [34] showed loss of microvilli and other flattened membrane areas on uterine epithelial cell surfaces at attachment and in humans several workers have pointed out similarities between the behaviour of rodent and human uterine epithelial cell apical plasmalemmas during early pregnancy [35-39] as we shall examine in more detail later. As if to highlight the commonality of these events, in a very different class of animals, apical plasma membrane flattening during early pregnancy has now been reported in viviparous lizards [40].

Apart from the purely morphological, this apical membrane flattening involves a major re-organization in membrane protein. As the apical membrane flattens, freezefracture studies in rats show an increase in large protein molecules which are visible as intramembranous particles (IMP) as well as the appearance of new arrays of protein particles [13]. Similar observations have been made in pigs [41] and rabbits [22]. Also using freeze-fracture electron microscopy, cholesterol increase in the apical plasma membrane of rats [42] and rabbits [22] has been reported. Thus at the molecular-morphological level too, some interesting commonalities in membrane behaviour occur even though the species studied have modes of placentation varying from heamochorial to epitheliochorial.

\section{UTERODOMES ('PINOPODES')-FEATURES OF THE APICAL PLASMA MEMBRANE OF SPE- CIAL CLINICAL INTEREST IN HUMANS}

One aspect of change in the plasma membrane of uterine epithelial cells has attracted much attention in the past few years. Originally termed 'pinopods' from studies in rats which established a pinocytotic function for them in this species [43], large, rounded, smooth-surfaced projections of the apical plasma membrane have been identified in the uterine epithelium of many species during early pregnancy ranging from rabbits and rodents through camels to human beings $[44,45]$. Because such smooth-surfaced projections occur during the receptive phase for blastocyst implantation in humans, these enigmatic structures have been the subject of many studies in humans which establish their utility as important indicators of normal endocrine progression as well as indicators of uterine receptivity for blastocyst implantation [45-50, 96].

Despite the undoubted utility of these structures in clinical medicine and indeed in clinical decision-making [48$50,96]$, the human 'pinopodes' do not have a significant pinocytotic function [95] and it has been suggested that the human structures be referred to as 'uterodomes' [45].

Function aside, the uterodomes in the present context, show yet another fascinating commonality in the plasma membrane of uterine epithelial cells in that they too represent a transformation of a microvillous plasma membrane into a smooth and flattened plasma membrane, albeit a bulging one in the case of these enigmatic structures.

Fig. 1 shows the typical pattern of change in the apical plasma membrane of rat uterine epithelial cells during early pregnancy and the return of apical microvilli after the period of uterine receptivity.

\section{TRANSFORMATION IN THE BASAL AND LATERAL PLASMA MEMBRANES}

While less obvious perhaps, and certainly studied in far fewer animals to date, the basolateral plasma membrane also undergoes its own form of 'transformation' during early pregnancy. Of particular note are changes in the lateral plasma membrane of uterine epithelial cells which were first observed in laboratory animals. The structures of major interest here are the various junctions which give epithelial cells their unique character. In uterine epithelial cells of rats, Murphy et al [51] showed that the tight junction on the lateral plasma membrane becomes much deeper during early pregnancy such that by the time of uterine receptivity it extends three-fold further down the lateral plasma membrane than it did when oestrogen was the dominant hormonal influence. This progesterone induced effect also results in the junction becoming more geometrically complex which probably reflects a reduced paracellular flow [51]. A similar increase in tight junction depth or complexity has also been shown in rabbits [52] and pigs [41] and reported in mice [53]. In the human uterus too, freeze-fracture studies show alterations to tight junctions which are most likely induced by progesterone but are not yet extensive enough to establish a common pattern [54]. Another junction of the lateral plasma membrane, the desmosome, has also been examined in a few species and both the morphological desmosome as well as key desmosomal proteins are similarly downregulated in mice [53], rats [55] and humans [56] by the time of uterine receptivity. The adherens junction as well as its associated terminal web is lost completely from the lateral plasma membrane by $d 6$ of pregnancy in rats but these structures are yet to be studied in other animals [92].

Thus collectively, all the components of the lateral plasma membrane junctional complex are 'transformed' in one way or another during the period leading to uterine receptivity.

The basal plasma membrane also undergoes considerable change during early pregnancy and like the lateral 


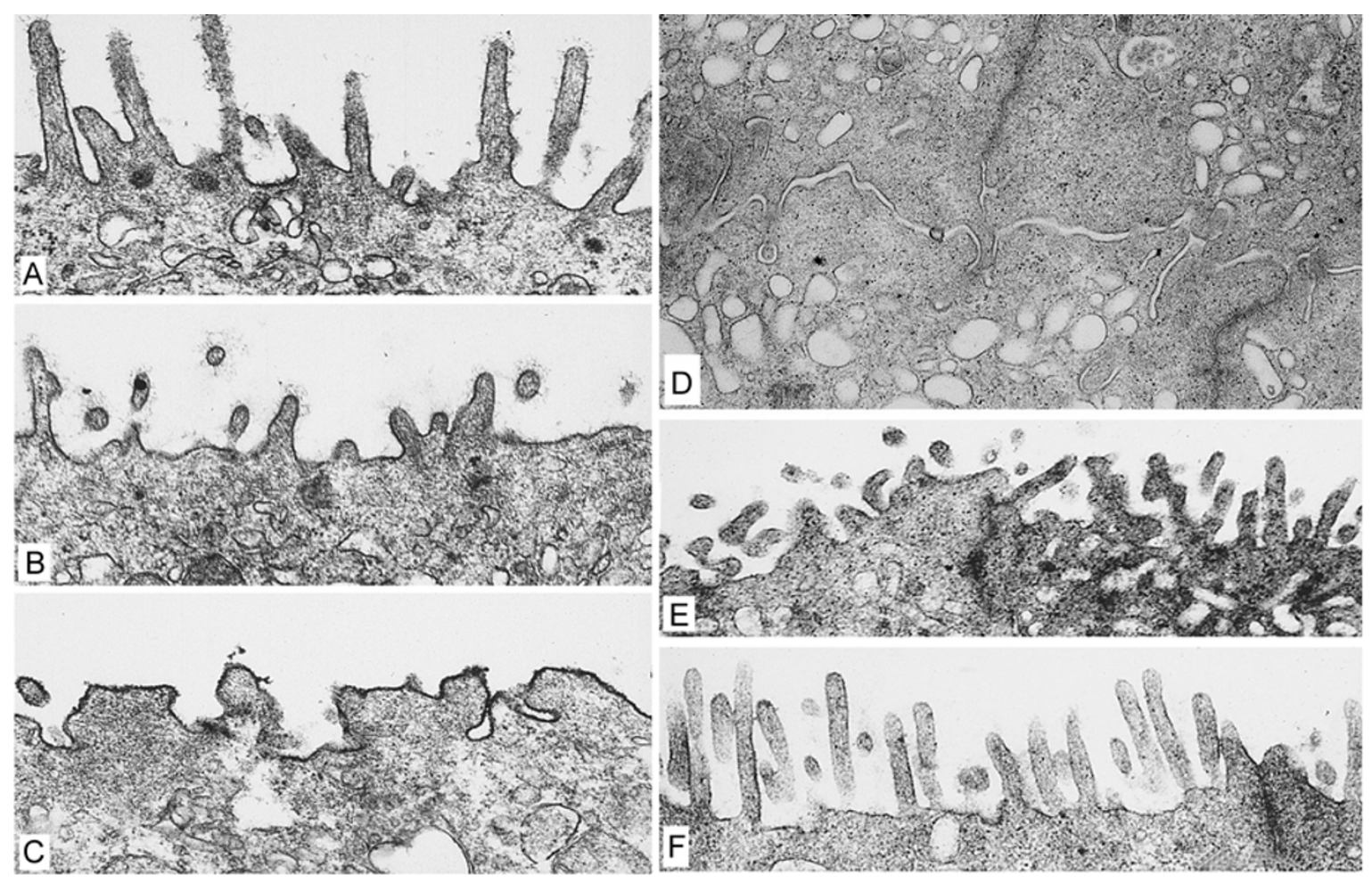

Fig. 1 shows the typical pattern of change in the apical plasma membrane of uterine epithelial cells in the rat during early pregnancy. (A) d 1 of pregnancy showing long regular microvilli. (B) shows d 3 with the apical microvilli being much shorter, less regular and less numerous. (C) on d 6, microvilli have disappeared and the apical membrane consists of irregular, flattened projections. (D) also d 6, showing opposing uterine epithelial cells closed down upon each other obliterating the lumen with the apical membranes running parallel to each other: this appearance is the same when a uterine epithelial cell opposes a blastocyst. (E) d 8, showing irregular microvilli returning to uterine epithelial cells in an inter-implantation site and (F) on d 9, showing regular microvilli again.

plasma membrane has been reported to become more tortuous in mice [57], rats [58], pigs [59] and rabbits [60]. Also common to this region of the membrane during early pregnancy in several species, is an increase in thickness of the basal lamina which has been reported in rats [58], rabbits [61] and humans [62].

\section{COMMON BEHAVIOUR OF SOME MOLECULAR MARKERS IN THE PLAMA MEMBRANE}

Several components of the carbohydrate-containing coat- or glycocalyx- of the apical plasma membrane have been shown to exhibit common behaviours across species. A reduction in surface negativity as well as a reduction in the presence of the morphological glycocalyx in most species so far studied including rats, mice, rabbits, monkeys and humans now seems to be reasonably well accepted $[3,6,44,63-65]$. Much recent interest has been focussed on one molecular component of the glycocalyx, the large mucin, MUC- 1 , which is reduced generally on the apical plasma membrane in rats [66], mice [67], monkeys [68], pigs [69] and sheep [97] and is also reduced locally in the region of the blastocyst in rabbits [70]. In the human clinical situation considerable interest has been shown in this molecule because of its possible involvement in idiopathic infertility [71]. At first studies not only showed no downregulation of this large mucin on human uterine epithelial cells around the period of uterine receptivity but an actual increase [72]. However, more recent studies on MUC-1 have shown that this important molecule is down-regulated quite specifically, but only, in the region of the implanting blastocyst [73]. Thus while the extent of the down regulation varies - from general to local, MUC-1 behaves similarly in several species during the period of uterine receptivity.

Molecules which are specifically up-regulated in the plasma membrane during early pregnancy have naturally been the subject of much interest because they may function as receptors for the blastocyst. Much work on carbohydrates has identified several epitopes which are up-regulated in 
A

B

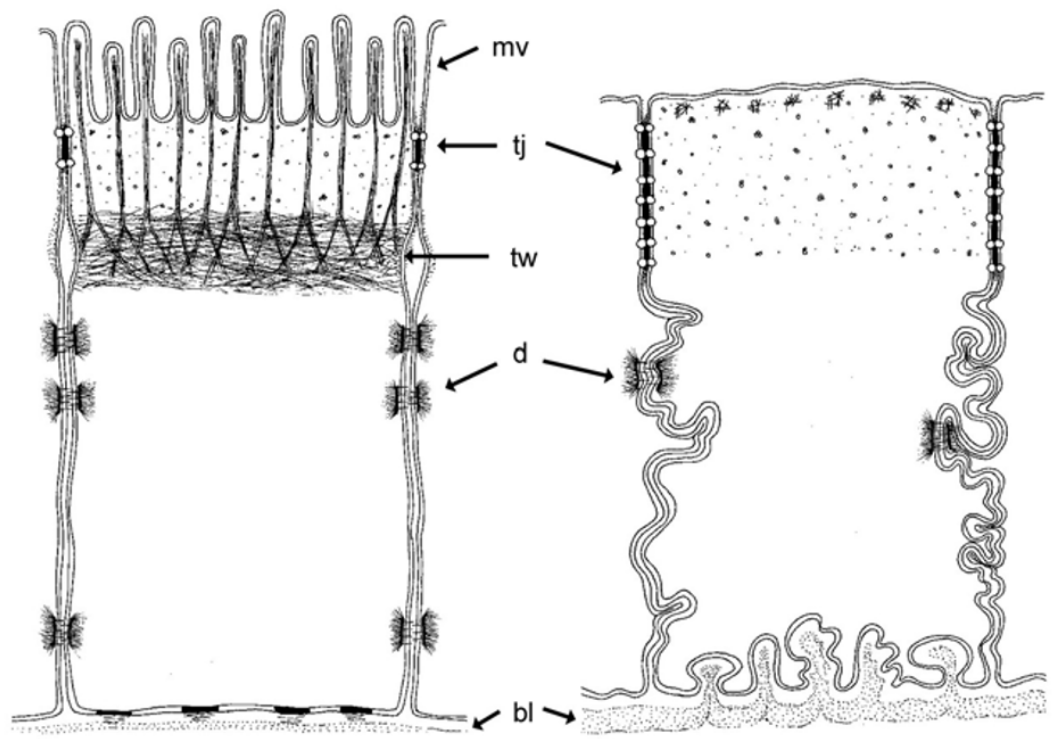

Fig. 2 Diagrams of uterine the epithelial cells highlighting some of the membrane phenomena referred to in the text. (A) Epithelial cells are shown in response to predominantly oestrogen stimulation and before receptivity (d 1). They display long microvilli (mv) and a relatively short tight junction ( $\mathrm{t}$ ) down the lateral plasma membrane. A prominent terminal web is present (tw) and desmosomes (d) are comparatively numerous. (B) Epithelial cells are shown following the "plasma membrane transformation' (d 6). The apical plasma membrane is smooth and flattened and the apical glycocalyx is lost which includes loss of Muc-1. Laterally, the tight junction extends three times as far down the lateral plasma membrane which is also more tortuous as is the basal plasma membrane which in addition has a thicker basal lamina (bl). Desmosomes (d) are considerably reduced along the lateral plasma membrane at this time and the terminal web is completely lost.

different species around the time of blastocyst attachment and which have in common numbers of glucosamine and fucose residues [74-80]. There is in addition emerging evidence that some integrins, cadherins and related receptors may be up-regulated in different membrane compartments in species so far examined which includes rodents, pigs, rabbits and humans during early pregnancy $[14,63$, 81-85]. Among these molecules, $\alpha_{v} \beta_{3}$ integrin appears to be particularly interesting and is either up regulated or becomes available due to the down regulation of MUC-1 in the plasma membrane of mouse, pig and human uterine epithelial cells during the receptive period [69, 86, 98]. Moreover, osteopontin, a secreted protein of uterine glandular epithelial cells which binds to the apical plasma membrane of luminal epithelial cells, may act as a common bridge between integrins on the apical plasma membrane and trophoblast in rodents, sheep and humans [97, 98].

Fig. 2 provides in diagrammatic form, an overview of many of the membrane changes referred to in the text.

\section{"THE PLASMA MEMBRANE TRANSFORMA- TION" CONCEPT}

The many changes which take place in the uterine epithelium during early pregnancy have been suggested to represent a loss of polarity in these cells [87] and this thought has been extended to suggest further that an epithelial-mesenchymal transition may occur in the cells during this time [88]. These perceptive insights highlight the critical importance of uterine epithelial cells in uterine receptivity and in one sense recall earlier suggestions on events in uterine epithelial cells. These early thoughts on uterine epithelial cells highlighted the apical plasma membrane flattening and led to the term 'attachment reaction' being used to describe some of the membrane changes which occur during early pregnancy [12]. This term was used to apply to those changes in the apical membrane of uterine epithelial cells upon contact with the blastocyst itself, or when opposing uterine epithelial cells came into physical contact at around the same time of early pregnancy in rats and mice [12]. In particular, the term indicated that in those species with an 'attachment reaction', closure of the uterine lumen was involved such that little or no luminal space remained [12]. However, as is now known, considerable change occurs in all compartments of the plasma 
membrane of uterine epithelial cells and these changes occupy most of early pregnancy in the rat and mouse with long, regular microvilli being converted into short, irregular structures as early as d 3-2 3 d before the blastocyst even enters the uterus $[7,89-90]$. As we have also seen, in a wide diversity of species, there are changes in the apical plasma membrane which have features in common with those seen in rats and mice and in many of these other species, closure of the uterine lumen does not occur. A common process is especially suggested by observations in animals with an epitheliochorial placenta like pigs and camels: here, as we have seen, the epithelium is not breached and the mature placenta consists of extensive interdigitation of very long trophoblastic and uterine epithelial microvilli throughout pregnancy. Nonetheless, before and during initial contact between uterine epithelial cells and the blastocyst, the regular microvilli of the uterine epithelium flatten out, much as they do in rats and mice, after which they return (within the next $48 \mathrm{~h}$ ) to form the interface of the mature placenta.

Moreover, as we have also seen, there are molecular alterations in the plasma membrane during early pregnancy which have common aspects across species and here MUC-1 is particularly instructive. Changes in the basal and lateral plasma membrane regions have also been documented in many species during early pregnancy in preparation for attachment, and these too show common aspects across species-especially some membrane junctional structures.

Therefore, to highlight that membrane alterations are a process during early pregnancy — not just an event at the time of attachment itself, to recognise the fact that both apical and basolateral alterations occur, that molecular changes are also evident, and that moreover, there appears to be a degree of commonality across species, we have suggested $[44,45,91-94]$ that alterations in the plasma membrane of uterine epithelial cells during early pregnancy be referred to collectively as "the plasma membrane transformation". This term encapsulates the concept of a common and necessary process of change in all compartments of the plasma membrane of uterine epithelial cells as characteristic, across species, of the development of uterine receptivity for implantation.

\section{REFERENCES}

1 Nilsson O. Structural differentiation of luminal membrane in rat uterus during normal and experimental implantations. Z Anat Entwikl-Gesch 1966; 125:152-9.

2 Ljungkvist I. Attachment reaction of rat uterine luminal epithelium IV. The cellular changes in the attachment reaction and its hormonal regulation. Fertil Steril 1972; 23:847-65.
3 Murphy CR. The plasma membrane of uterine epithelial cells: structure and histochemistry. Stuttgart Gustav Fischer 1993; $68 \mathrm{pp}$.

4 Tachi S, Tachi C, Lindner HR. Ultrastructural features of blastocyst attachment and trophoblastic invasion in the rat. J Reprod Fert 1970; 21:37-56.

5 Smith AF, Wilson IB. Cell interaction at the maternal-embryonic interface during implantation in the mouse. Cell Tiss Res 1974; 152:525-42.

6 Schlafke S, Enders AC. Cellular basis of interaction between trophoblast and uterus at implantation. Biol Reprod 1975; 12: 41-65.

7 Luxford KA, Murphy CR. Reorganization of the apical cytoskeleton of uterine epithelial cells during early pregnancy in the rat: a study with myosin subfragment 1 . Biol Cell 1992; 74:195-202.

8 Pollard RM, Finn, CA. Influence of the trophoblast upon differentiation of the uterine epithelium during implantation in the mouse. J Endocrinol 1974; 62:669-74

9 Png F, Murphy CR. Closure of the uterine lumen and the plasma membrane transformation do not require blastocyst implantation. Europ J Morph 2000; 38:122-7.

10 Ljungkvist I, Nilsson O. Ultrastructure of rat uterine luminal epithelium at functional states compatible with implantation. Z Anat Entwickl-Gesch 1971; 135:101-7.

11 Murphy CR, Rogers AW. Effects of ovarian hormones on cell membranes in the rat uterus. III. The surface carbohydrates at the apex of the luminal epithelium. Cell Biophys 1981; 3:305-20

12 Nilsson O. Some ultrastructural aspects of ovo-implantation. In: Ovo-implantation, human gonadotropins and prolactin (Hubinont PO, Leroy F, Robyn C, Leleux P, eds) S. Karger, Basel. 1970; 52-72.

13 Murphy CR, Swift JG, Mukherjee TM, Rogers AW. Changes in the fine structure of the apical plasma membrane of endometrial epithelial cells during implantation in the rat. J Cell Sci 1982; 55: 1-12.

14 Hyland RA, Shaw TJ, Png FY, Murphy CR. Pan-cadherin concentrates apically in uterine epithelial cells during uterine closure in the rat. Acta Histochem 1998; 100:75-81.

15 McLaren A, Nilsson O. Electron microscopy of luminal epithelium separated by beads in the pseudopregnant mouse uterus. $J$ Reprod Fertil 1971; 26:379-81.

16 Psychoyos A. Hormonal control of ovoimplantation. Vitams Horms 1973; 31:201-56.

17 Ljungkvist I. Implantation and attachment reaction of rat uterine luminal epithelium at a high dose of estradiol. J Endocrinol 1972; 55:515-8.

18 Smith AF. Ultrastructure of the uterine luminal epithelium at the time of implantation in ageing mice. J Reprod Fert 1975: 42:183-5.

19 Png F, Murphy CR. The plasma membrane transformation does not last: microvilli return to the apical plasma membrane of uterine epithelial cells after the period of uterine receptivity. Europ J Morphol 1997; 35:19-24.

20 Dantzer V. Electron microscopy of the initial stages of placentation in the pig. Anat Embryol 1985; 172:281-93.

21 Blankenship TN, Given RL, Parkening TA. Blastocyst implantation in the chinese hamster (Cricetulus griseus). Am J Anat 1990; 187:137-57

22 Winterhager E, Denker HW. Changes in lipid organization of uterine epithelial cell membranes at implantation in the rabbit. 
Troph Res 1990; 4:323-38.

23 Potts DM, Racey PA. A light and electron microscopic study of early development in the bat Pipistrellus pipistrellus. Micron $1971 ; 2: 322-48$

24 Oliveira SF, Rasweiler JJ IV, Badwaik NK. Advanced oviductal development, transport to the preferred implantation site, and attachment of the blastocyst in captive-bred, short-tailed fruit bats, Carollia perspicillata. Anat Embryol 2000; 201:357-81.

25 Aitken RJ, Burton J, Hawkins J, Kerr-Wilson R, Short RV, Steven DH. Histological and ultrastructural changes in the blastocyst and reproductive tract of the roe deer, Capreolus capreolus, during delayed implantation. J Reprod Fert 1973; 34:481-93.

26 Allen WR, Hamilton DW, Moor RM. The origin of equine endometrial cups. II. Invasion of the endometrium by trophoblast. Anat Rec 1973; 177:485-502.

27 Guillomot M, Flechon JE, Wintenberger-Torres S. Conceptus attachment in the ewe: an ultrastructural study. Placenta 1981; 2:168-82.

28 Leiser R, Koob B. Development and characteristics of placentation in a carnivore, the domestic cat. J Exp Zool 1993; 266:642-56.

29 Wango EO, Wooding FBP, Heap RB. The role of trophoblastic binucleate cells in implantation in the goat: a morphological study. J Anat 1990; 171:241-57.

30 Wooding FBP, Morgan G. Cellular interactions during implantation in ruminants. In: molecular and cellular aspects of periimplantation processes. Dey SK (ed). New York, Springer, 1995:153-67.

31 Skidmore JA, Wooding FBP, Allen WR. Implantation and early placentation in the one-humped camel (Camelus dromedarius). Placenta 1996; 17:253-62.

32 Abd-Elnaeim MM, Pfarrer C, Saber AS, et al. Fetomaternal attachment and anchorage in the early diffuse epitheliochorial placenta of the camel (Camelus dromedarius). Cells Tiss Organs 1999; 164:141-54.

33 Roberts CT, Breed WG. Embryonic-maternal interactions at implantation in the fat-tailed dunnart, a dasyurid marsupial. Anat Rec 1994; 240:59-76.

34 Enders AC, Hendrickx AG, Schlafke S. Implantation in the rhesus monkey: initial penetration of endometrium. Am J Anat 1983; 167:275-98.

35 Nilsson O. Correlation of structure to function of the luminal cell surface in the uterine epithelium of mouse and man. Z Zellforsch 1962; 56:803-8.

36 Martel D, Frydman R, Glissant M, Maggioni C, Roche D, Psychoyos A. Scanning electron microscopy of postovulatory human endometrium in spontaneous and cycles stimulated by hormone treatment. J Endocrinol 1987; 114:319-24.

37 Martel D, Monier MN, Roche D, Psychoyos A. Hormonal control of pinopode formation at the uterine luminal surface. Hum Reprod 1991; 6:597-603.

38 Murphy CR, Rogers PAW, Leeton J, Hosie M, Beaton L, Macpherson A. Surface ultrastructure of uterine epithelial cells in women with premature ovarian failure following steroid hormone replacement. Acta Anat 1987; 132:253-5.

39 Murphy CR, Rogers PAW, Kovacs G, Hailes J, Hosie M, Beaton L. Early evaluation of postmenopausal hormonal steroid therapy by scanning electron microscopy of the uterine epithelium. Acta Anat 1990; 138:364-6.

40 Murphy CR, Hosie MJ, Thompson MB. The plasma mem- brane transformation facilitates pregnancy in both reptiles and lizards. Comp Biochem Physiol A 2000; 127:433-9.

41 Johnson SA, Morgan G, Wooding FBP. Alterations in uterine epithelial tight junction structure during the oestrous cycle and implantation in the pig. J Reprod Fert 1988; 83:915-22.

42 Murphy CR, Dwarte D. Increase in cholesterol in the apical plasma membrane of uterine epithelial cells during early pregnancy in the rat. Acta Anat 1987; 128:76-9.

43 Enders AC, Nelson DM. Pinocytotic activity of the uterus of the rat. Am J Anat 1973; 138:277-300.

44 Murphy CR. The cytoskeleton of uterine epithelial cells: a new player in uterine receptivity and the plasma membrane transformation. Hum Reprod Update 1995; 1:567-80.

45 Murphy CR. Pinopods- or uterodomes? Hum Reprod 2000; 15: 2451-4.

46 Bentin-Ley U, Sjogren A, Nilsson L, Hamberger L, Larsen JF, Horn T. Presence of uterine pinopodes at the embryo-endometrial interface during human implantation in vitro. Hum Reprod 1999; 14:515-20.

47 Nikas G. Cell-surface morphological events relevant to human implantation. Hum. Reprod. 1999; 14 Supp 1 2:37-44.

48 Nikas G. Pinopodes as markers of endometrial receptivity in clinical practice. Hum Reprod 1999; 14 Supp 2:99-106.

49 Adams SM, Gayer N, Terry V, Murphy CR. Manipulation of the follicular phase: uterodomes and pregnancy- is there a correlation? BioMED Central: Pregnancy and Childbirth 2001; 1:2. URL http://www.biomedcentral.com/1471-2393/1/2/.

50 Adams SM, Terry V, Murphy CR. A successful pregnancy following SEM fine-tuning of hormonal priming. BioMED Central: Pregnancy and Childbirth 2001; (in press).

51 Murphy CR, Swift JG, Mukherjee TM, Rogers AW. The structure of tight junctions between uterine luminal epithelial cells at different stages of pregnancy in the rat. Cell Tiss Res 1982; 223: 281-6.

52 Winterhager E, Kuhnel W. Alterations in intercellular junctions of the uterine epithelium during the preimplantation phase in the rabbit. Cell Tiss Res 1982; 224:517-26.

53 Illingworth IM, Kiszka I, Bagley S, Ireland GW, Garrod DR, Kimber SJ. Desmosomes are reduced in the mouse uterine lumonal epithelium during the preimplantation period of pregnancy: a mechanism for facilitation of implantation. Biol Reprod 2000; 63:1764-73.

54 Murphy CR, Rogers PAW, Hosie MJ, Leeton J, Beaton L. Tight junctions of human uterine epithelial cells change during the menstrual cycle: a morphometric study. Acta Anat 1992; 144:36-8.

55 Preston AM, Lindsay LA, Murphy CR. Progesterone treatment and the progress of early pregnancy reduce desmoglein $1 \& 2$ staining along the lateral plasma membrane in rat uterine epithelial cells (submitted), and unpublished data.

56 Sarani SA, Ghaffari-Novin M, Warren MA, Dockery P, Cooke ID. Morphological evidence for the 'implantation window' in human luminal endometrium. Hum Reprod 1999; 14:3101-6.

57 Blankenship TN, Given RL. Penetration of the uterine epithelial basement membrane during blastocyst implantation in the mouse. Anat Rec 1992; 233:196-204.

58 Shion YL, Murphy CR. The basal plasma membrane and lamina densa of uterine epithelial cells are both altered during early pregnancy and by ovarian hormones in the rat. Europ J Morphol 1995; 33:257-64. 
59 Keys JL, King GJ. Effects of topical and systemic estrogen on morphology of porcine uterine luminal epithelia. Biol Reprod 1992; 46:1165-75.

60 Larsen JF. Electron microscopy of the uterine epithelium in the rabbit. J Cell Biol 1962; 14:49-64.

61 Marx M, Winterhager E, Denker HW. Penetration of the basal lamina by processes of the uterine epithelial cells during implantation in the rabbit. Troph Res 1990; 4:417-30.

62 Dockery P, Khalid J, Sarani SA, et al. Changes in basement membrane thickness in the human endometrium during the luteal phase of the menstrual cycle. Human Reprod 1998; 4:485-6.

63 Wegner CC, Carson DD. Cell adhesion processes in implantation. Oxf Rev Reprod Biol 1994; 16:87-137.

64 Aplin JD. The cell biology of human implantation. Placenta 1996; 17:269-75.

65 Lopata A. Blastocyst-endometrial interaction: an appraisal of some old and new ideas. Mol Hum Reprod 1996; 2:519-25.

66 DeSouza MM, Mani SK, Julian JJ, Carson DD. Reduction of mucin-1 expression during the receptive phase in the rat uterus. Biol Reprod 1998; 58:1503-7.

67 Surveyor GA, Gendler SJ, Pemberton L, et al. Expression and steroid hormonal control of muc-1 in the mouse uterus. Endocrinol 1995; 136:3639-47.

68 Hild-Petito S, Fazleabas AT, Julian J, Carson DD. Mucin (muc1) expression is differentially regulated in uterine luminal and glandular epithelia of the baboon (Papio anubis). Biol Reprod 1996; 54:939-47.

69 Bowen JA, Bazer FW, Burghardt RC. Spatial and temporal analyses of integrin and Muc-1 expression in porcine uterine epithelium and trophectoderm in vivo. Biol Reprod 1996; 55:1098106.

70 Hoffman LH, Olson GE, Carson DD, Chilton BS. Progesterone and implanting blastocysts regulate muc 1 expression in rabbit uterine epithelium. Endocrinol 1998; 139:266-71.

71 Hey NA, Li TC, Devine P, Graham RA, Aplin JD. MUC1 in secretory phase endometrium: expression in precisely dated biopsies and flushings from normal and recurrent miscarriage patients. Hum Reprod 1995; 10:2555-662.

72 Aplin JD, Hey NA, Graham RA. Human endometrial MUC! Carries keratin sulphate: characteristic glycoforms in the luminal epithelium at receptivity. Glycobiol 1998; 8:269-76.

73 Meseguer M, Aplin JD, Caballero-Campo P, et al. Human endometrial mucin MUC1 is up-regulated by progesterone and down-regulated in vitro by the human blastocyst. Biol Reprod 2001; 64:590-601.

74 Murphy CR, Turner VT. Glycocalyx carbohydrates of uterine epithelial cells increase during early pregnancy in the rat. J Anat 1991; 177:109-15.

75 Whyte A, Binns RM. Adhesion molecule expression and infiltrating maternal leucocyte phenotypes during blastocyst implantation in the pig. Cell Biol Internat 1994; 18:759-66.

76 Kimber SJ, Illingworth IM, Glasser SR. Expression of carbohydrate antigens in the rat uterus during early pregnancy and after ovariectomy and steroid replacement. J Reprod Fertil 1995; 103: 75-87.

77 Kimber SJ, Sidhu SS. Control of expression of the H-type-1 histo-blood group antigen in th murine endometrial epithelium and its role in blastocyst adhesion. Human Reprod 1997; 12 Natl Suppl:58-64.
78 Isaacs J, Murphy CR. Expression of the carbohydrate antigen CD 15 in rat uterine epithelial cells during the early stages of pregnancy. Europ J Morphol 1998; 36:49-56.

79 Wang XQ, Zhu ZM, Fenderson BA, Zeng GQ, Cao YJ, Jiang GT. Effects of monoclonal antibody directed to $\mathrm{Le}^{\mathrm{y}}$ on implantation in the mouse. Mol Hum Reprod 1998; 4:295-300.

80 Powell JK, Glasser SR, Woldesenbret S, Burghardt RC, Newton GR. Expression of carbohydrate antigens in the goat uterus during early pregnancy and on steroid-treated polarized uterine epithelial cells in vitro. Biol Reprod 2000; 62:277-84.

81 Hohn HP, Huch G, Tlolka U, Denker HW. Differential expression of CD 44 in rabbit uterine epithelium during early pregnancy. Acta Anat 1995; 152:185-94.

82 Simon C, Gimeno MJ, Mercader A, et al. Cytokines-adhesion molecules-invasive proteinases. The missing paracrine/autocrine link in embryonic implantation? Mol Hum Reprod 1996; 2:405-24.

83 Simon C, Gimeno MJ, Mercador A, et al. Embryonic regulation of integrins $\alpha_{3}, \beta_{4}$, and $\alpha_{1}$ in human endometrial epithelial cells in vitro. J Clin Enocrinol Metab 1997; 82:2607-16.

84 Simon C, Krussel J, Valbuena D, et al. Interleukin-1 receptor antagonist prevents embryonic implantation by a direct effect on the endometrial epithelium. Fertil Steril 1998; 70:896-906.

85 Fazleabas AT, Bell SC, Fleming S, Sun J, Lessey BA. Distribution of integrins and the extracellular matrix proteins in the baboon endometrium during the menstrual cycle and early pregnancy. Biol Reprod 1997; 56:348-56.

86 1llera MJ, Cullinan E, Gui Y, Yuan L, Beyler SA, Lessey BA. Blockade of the $\alpha_{v} \beta_{3}$ integrin adversely affects implantation in the mouse. Biol Reprod 2000; 62:1285-90.

87 Denker HW. Trophoblast-endometrial interactions at embryo implantation: a cell biological paradox. Troph Res 1990; 4:3-29.

88 Denker HW. Endometrial receptivity: cell biological aspects of an unusual epithelium. A review. Ann Anat 1994; 176:53-60.

89 Jones BJ, Murphy CR. A high resolution study of the glycocalyx of rat uterine epithelial cells during early pregnancy with the field emission gun scanning electron microscope. J Anat 1994; 185:443-6.

90 Bucci M, Murphy CR. Differential alterations in the distribution of three phosphatase enzymes during the plasma membrane transformation of uterine epithelial cells in the rat. Cell Biol Internat 1999; 31:21-30.

91 Murphy CR. Commonality within diversity: the plasma membrane transformation of uterine epithelial cells during early placentation. J Assist Reprod Genet 1998; 15:179-83.

92 Murphy CR. Junctional barrier complexes undergo major alterations during the plasma membrane transformation of uterine epithelial cells. Hum Reprod 2000; 15 Suppl 3:182-8.

93 Murphy CR, Shaw TJ. Plasma membrane transformation: a common response of uterine epithelial cells during the peri-implantation period. Cell Biol Internat 1994; 18:1115-28.

94 Murphy CR. The plasma membrane transformation: a key concept in uterine receptivity. Reprod Med Review 2001; 9:197-208.

95 Adams SM, Gayer N, Hosie MJ, Murphy CR. Human uterodomes (pinopods) do not display pinocytotic function. Human Reprod 2002; 17:1980-6.

96 Stavreus-Evers A, Aghanova L, Brismar H, Eriksson H, Landgren B-M, Hovatta O. Co-existence of heparin-binding epidermal growth facto-like growth factor and pinopodes in human endometrium at the time of implantation. Mol Human Reprod 
2002; 8:765-9.

97 Johnson GA, Bazer FW, Jaeger LA, et al. Muc-1, integrin and osteopontin expression during the implantation cascade in sheep. Biol Reprod 2001; 820-8.
98 Johnson GA, Burghardt RC, Spencer TE, Newton GR, Ott TL, Bazer FW. Ovine osteopontin II. Osteopontin and $\alpha_{v} \beta_{3}$ integrin expression in the uterus and conceptus during the peri-implantation period. Biol Reprod 1999; 61:892-9. 